\title{
Biomédica
}

Semblanza Académica

\section{In Memoriam, el Dr. Francisco Javier Torre Bolio y su compromiso con el "ser para servir"}

Esteban Aguilar-Vargas ${ }^{1}$, Nina Méndez-Dominguez ${ }^{2}$.

${ }^{1}$ Campus de Ciencias de la Salud, Universidad Marista de Mérida, México. ${ }^{2}$ Cinvestav-IPN, Departamento de Ecología Humana. Mérida, México.

\section{Autor para correspondencia}

Nombre: Nina Méndez-Domínguez

Institución: Cinvestav-IPN

Departamento: Departamento de Ecología Humana

Dirección: Mérida, Yucatán, México

E-mail: ninuxka@hotmail.com

Recibido: el 19 de agosto de 2016 Aceptado para publicación: el 24 de agosto de 2016

Copyright (C) 2016 por autores (s) y Revista Biomédica.

Este trabajo esta licenciado bajo las atribuciones de la Creative Commons (CC BY).

http://creativecommons.org/licenses/by/4.0/

(c) (†) Open Access 


\section{Aguilar-Vargas et al}

Nuestros caminos convergieron en el año 2013, que fue entonces cuando tuve la fortuna de que fuera mi maestro, pero sobre todo, tuve la oportunidad de aprender de él en las aulas de la escuela de medicina de la Universidad Marista de Mérida. Mucho más allá de ser el profesor de la cátedra de neumología, el Dr. Torre Bolio nos instruyó, tanto en aspectos académicos, como humanos, teniendo para con nosotros, sus afortunados alumnos, un trato cálido, siempre con la mayor disponibilidad de enseñar con una sonrisa, pero a la vez templado por su seriedad y formalidad.

De voz de sus colegas pude escuchar algunos comentarios con respecto al Dr. Javier, entre los que destacan: “¡Un Médico íntegro! Tuvimos oportunidad de trabajar juntos a nivel hospitalario -y he de decir- que irradiaba humanidad y trato profesional. Un excelente académico que estoy seguro deja huella en muchos médicos en formación. "Un hombre bueno. Javier vive en nosotros." Dr. LAMT, en comunicación personal. "Un caballero... dirigido hacia la constante enseñanza de que la medicina, no es medicina y el médico, no es médico si no es capaz de tener como objetivo primario el de servir a las demás personas y ser capaz de poner de primero al prójimo". -MIP OJAI-

El Dr. Torre Bolio, a través de cada anécdota y cada relato, nos dejaba una enseñanza de vida, con el objetivo de forjar nuestra personalidad y mejorar nuestra actitud, buscando que desarrollemos y reforcemos las habilidades deseables para enfrentar las viscisitudes que enfrentaríamos como médicos y miembros de la sociedad.

Son numerosas las experiencias agradables que los colegas del Dr. Javier expresan, entre las cuales, me permito hacer referencia a la siguiente: "Conocí a Javier cuando recién llegué de la residencia, hicimos un gran equipo. Una vez me dijo que le gustaba pescar, pero no disfrutaba cazar; esto se debía a que, en alguna ocasión, durante su juventud, fue de caza y al sentir el arma en sus manos, no tuvo deseos de apuntar ni disparar a animal alguno." -Dr. RRC- Este recuerdo refleja el espíritu de un médico comprometido con la vida y la benevolencia.

El Dr. Torre Bolio, cursó la licenciatura de Médico Cirujano en la Facultad de Medicina de la Universidad Autónoma de Yucatán en el año de 1982, optando por especializarse en Medicina Interna para, posteriormente, finalizar la subespecialidad en neumología en el año 2000.

Si bien ejerció la docencia, cabe destacar que ésta, no era su actividad principal, puesto que también ejerció la práctica médica privada e institucional en los que ocupó diferentes cargos, como por ejemplo, en la práctica médica privada fungió como coordinador de la clínica de apnea y sueño, en el Instituto Mexicano del Seguro Social laboró como médico especialista y así mismo, representó el papel de jefe de enseñanza e investigación en un hospital privado. 
Basó su práctica clínica en la empatía hacia sus pacientes y a su valiosa experiencia, pero también fundamentó sus métodos de tratamiento científicamente, ya que participó en la generación de las guías para el diagnóstico y tratamiento de la enfermedad pulmonar obstructiva crónica, derivadas del Cuarto Consenso Mexicano para el Diagnóstico y Tratamiento de la EPOC, mismas que aún se aplican en la práctica clínica(1). Adicionalmente, fue miembro de la Asociación Mexicana, Latinoamericana y Europea de Neumología, fue jefe de la sección de neumología para adultos y secretario de la Sociedad Mexicana de Neumología y Cirugía de Tórax.

$\mathrm{Su}$ interés por mejorar los tratamientos convencionales de la bronquitis crónica, lo llevaron a investigar acerca de nuevas terapias y por ello, aportó al conocimiento y avance de la ciencia médica la eficacia clínica, bacteriológica y la seguridad del esquema de gatifloxacina oral en el tratamiento de la exacerbación aguda de la bronquitis crónica. Así mismo, participó con el grupo de investigación que estudió mediante un ensayo clínico aleatorizado y doble ciego, la eficacia de moxifloxacino en la prevención de las exacerbaciones de enfermedad pulmonar obstructiva crónica.

Por varios años, el Dr. Torre Bolio formó parte de la Red de Enfermedad Pulmonar Obstructiva Crónica de México, la cual fue una iniciativa que aplicó medidas de promoción, difusión, educación médica continua y diagnóstico oportuno para mejorar el abordaje y calidad de vida de los pacientes.

Un día, el Dr. Torre Bolio, nos regaló a sus alumnos un objeto totalmente nuevo, sin pedirnos más recompensa que la de usarlo "para bien”. ¿Quien nos hubiera dicho que, meses más tarde, estos equipos (flujómetros, para evaluar la función pulmonar) nos servirían para realizar investigaciones epidemiológicas que difundiríamos en congresos internacionales! Este gesto desinteresado de nuestro querido doctor, nos dió herramientas para forjar una formación íntegra como médicos, tanto a nivel académico por la difusión de nuevo conocimiento, como a nivel moral y humano; el simple hecho de brindar recursos a sus alumnos, pacientes y personas cercanas, sin esperar nada a cambio nos demostró la gran calidad de ser humano que era y que nos hace lamentar tanto la gran pérdida que generó su ausencia.

Siempre tendré presente sus enseñanzas, entre las que destaca la de que el ser humano tiene la capacidad de renovarse día a día, en el campo profesional, el campo académico y, por supuesto, en el campo humano. Fue un ejemplo vivo de humildad, ecuanimidad, constancia, pero más que nada, de actitud de servicio, esto es, del ser para servir.

El 27 de julio de 2016, sus alumnos recibimos, cada quien desde su hospital sede de internado, la noticia de la gran pérdida de nuestro profesor quien, a la edad de 59 años, había fallecido. A pesar de 


\section{Aguilar-Vargas et al}

su ausencia física, las enseñanzas y el ejemplo de vida que transmitió permanecerán para siempre en nuestra memoria y orientará nuestro ya próximo acto médico y humano.

Para finalizar, si me pidieran de algún modo definir, de manera precisa, el proceder del Dr. Francisco Javier Torre Bolio, sin dudarlo, escogería las palabras de William Ösler, "El valor de la experiencia está no en ver mucho, si no en ver sabiamente"(2).

\section{Referencias}

1. Sansores RH, Kaldman MA, Argote-Greene LM, Flores EVC, Suárez CC, Angulo SC, et al. Guías para el Diagnóstico y Tratamiento de la Enfermedad Pulmonar Obstructiva Crónica Derivadas del Cuarto Consenso Mexicano para el Diagnóstico y Tratamiento de la EPOC. Neumología y Cirugía de Tórax. 2012;71(S1):8-89.

2. Osler W, Silverman M, Murray T, Bryan C. The Quotable Osler: American College of Physicians; 2008. 